\title{
Atmospheric winter response to a projected future Antarctic sea-ice reduction: a dynamical analysis
}

\author{
Jürgen Bader • Martin Flügge • Nils Gunnar Kvamstø • \\ Michel D. S. Mesquita $\cdot$ Aiko Voigt
}

Received: 27 February 2012/Accepted: 21 August 2012/Published online: 16 September 2012

(c) Springer-Verlag 2012

\begin{abstract}
Several studies have analysed the atmospheric response to sea-ice changes in the Arctic region, but only few have considered the Antarctic. Here, the atmospheric response to sea-ice variability in the Southern Hemisphere is investigated with the atmospheric general circulation model ECHAM5. The model is forced by the present and a projected future seasonal cycle of Antarctic sea ice. In September, the mean atmospheric response exhibits distinct similarities to the structure of the negative phase of the Southern Annular Mode, the leading mode of Southern Hemisphere variability. In the reduced Antarctic sea-ice integration, there is an equatorward shift of the Southern Hemisphere mid-latitude jet and the storm tracks. In contrast to a recent previous study, our findings indicate that a substantial impact of Southern Hemispheric future sea-ice reduction on the mid-latitude circulation cannot be ruled out.
\end{abstract}

\section{Introduction}

In recent years there has been an increase in the amount of literature on the impact of Arctic sea-ice loss on the atmospheric circulation, while only relatively few papers have addressed the response to Antarctic sea-ice anomalies.

\footnotetext{
J. Bader $(\bowtie) \cdot$ A. Voigt

Max Planck Institute for Meteorology,

Bundesstraße 53, 20146 Hamburg, Germany

e-mail: juergen.bader@zmaw.de

J. Bader · M. D. S. Mesquita

Bjerknes Centre for Climate Research,

Uni Research, Bergen, Norway

M. Flügge $\cdot$ N. G. Kvamst $\varnothing$

Geophysical Institute, University of Bergen, Bergen, Norway
}

The greater interest in the Arctic might be related to the observed substantial negative trends in Arctic sea-ice extent over the recent decades (Serreze et al. 2007) and its record minimum in 2007. In contrast, the observed Antarctic sea-ice extent has increased over the last 50 years (Turner et al. 2007; Turner and Overland 2009). However, sea ice is projected to shrink in both the Arctic and Antarctic under all SRES future scenarios (IPCC 2007). The investigation of the atmospheric response to projected seaice reductions in the Antarctic is hence highly relevant.

Sea-ice changes are associated with relatively large $\left(\approx 100 \mathrm{Wm}^{-2}\right)$ surface heat flux changes (Alexander et al. 2004). Sea-ice variability has therefore the possibility to substantially impact the atmospheric circulation and storm tracks (Mesquita et al. 2010). The surface heat flux changes can have a "direct" thermodynamic effect on the atmosphere which are described in Kushnir et al. (2002) by a transformed version of the hypsometric equation for the $500 \mathrm{hPa}$ height. Moreover, sea-ice anomalies impact the low-level baroclinicity and therefore the genesis of baroclinic eddies/waves (Kushnir et al. 2002; Brayshaw et al. 2008). There is growing evidence that reductions in Arctic sea ice, especially in the Barents Sea, might impact the mid-latitudinal circulation. Modeling studies show that reductions in Arctic sea ice induce a negative phase of the winter North Atlantic Oscillation (NAO) (e. g. Magnusdottir et al. 2004; Seierstad and Bader 2009; Bader et al. 2011). Kidston et al. (2011) conduct numerical experiments with a reduced and enhanced Antarctic sea-ice cover: the observed sea-ice edge in the Southern Hemisphere $(\mathrm{SH})$ is expanded or contracted by $7^{\circ}$ latitudes. While Kidston et al. (2011) find a strong poleward shift of the SH mid-latitude jet for increased sea-ice cover, they saw only very little jet changes when the sea ice is reduced. Kidston et al. (2011) therefore concluded that a future 
decrease in Antarctic sea ice is unlikely to have a profound impact on the Southern Hemisphere mid-latitude circulation. In contrast, Menéndez et al. (1999) completely removed the Antarctic sea ice in an AGCM study and found a dipole like barotropic zonal mean zonal wind response. Poleward of approximately $45^{\circ} \mathrm{S}$ the zonal wind was substantially reduced whereas equator-ward of this latitude the wind was enhanced, associated with an equatorward shift of the mid-latitude jet.

The current scientific knowledge is not conclusive whether SH sea-ice reductions substantially matter for the circulation in the mid-latitudes. Further analysis and experiments are needed to shed light on the role of Antarctic sea ice on the extra-tropical atmospheric dynamics. In the present paper, the atmospheric model ECHAM5 is forced with a projected Antarctic sea-ice cover and the atmospheric response is analysed during Southern Hemisphere winter months July to August (JAS). Since the projected sea-ice field comes from a coupled ocean-atmosphere-sea-ice model forced by the SRES A1B scenario, it is less 'idealised' than the forcing fields used by Menéndez et al. (1999) and Kidston et al. (2011). This paper addresses the following questions:

- Does a reduction in Antarctic sea-ice cover have a substantial impact on the mid-latitude $\mathrm{SH}$ atmospheric circulation?

- Are these changes in the mid-latitude SH atmospheric circulation in "analogy" to previous experiments with reduced Arctic sea-ice (e. g. by Seierstad and Bader (2009))? i.e., does a reduction in Antarctic sea ice lead to a weaker Southern Annular Mode (SAM)?

- What are the dynamical mechanisms that lead to the changes in the atmospheric circulation?

\section{Model experiments and methods}

Two 31-year long experiments are performed with the atmospheric general circulation model ECHAM5 (Roeckner et al. 2003), which has been previously used for sea-ice experiments (see e. g. Seierstad and Bader 2009; Mesquita et al. 2010) and SH storm analysis (e. g. Bengtsson et al. 2006). The model is run at $\mathrm{T} 42\left(\approx 2.8^{\circ} \times 2.8^{\circ}\right)$ horizontal resolution with 19 vertical levels. The "present-day" integration is forced by the present-day climatological seasonal cycle of sea surface temperatures (SSTs) and sea ice concentrations (SICs) derived from the 1981-1999 Hadley Centre observations (Rayner et al. 2003). The Antarctic SIC field in the second experiment is changed to a projected climatological seasonal cycle, based on the 2081-2099 ECHAM5/MPI-OM IPCC SRES A1B scenario output of three ensemble members. The Antarctic sea-ice thickness is fixed at $1 \mathrm{~m}$ in both experiments. For the experiment with projected sea ice, the SSTs in the Southern Hemisphere have been replaced with projected SSTs at grid points where sea ice was changed in order to be physically consistent. Elsewhere, the SSTs are the same as in the present-day experiment. There are no changes in sea ice or SST in the Northern Hemisphere. In the Southern Hemisphere all tropical/subtropical and most of the mid-latitude SSTs are unchanged. Both the present-day simulation and the simulation with decreased Antarctic sea-ice are run for 31 year. Results are averaged over the last 30 years; the first year is excluded from the analysis due to spin-up effects. Figure 1a shows the reduction in SIC in the Southern Hemisphere winter (JAS) between the two experiments (projected minus present-day Antarctic sea ice). The sea-ice reduction in September covers a slightly larger area (not shown). Figure 1b, c show the seasonality of differences in latent plus sensible heat fluxes between the two experiments (projected minus present-day Antarctic sea ice). Positive values are indicative of increased ocean-to-atmosphere heat fluxes when sea-ice concentration is reduced. To distinguish between forcing and response only positive values are shown since the simulated negative SAM response (discussed later) itself is associated with negative heat fluxes that are only indirectly linked to sea-ice anomalies. It is clear that the largest response in heat forcing is during the Southern Hemispheric winter season. Overall, the experimental setup is similar to the one used in Seierstad and Bader (2009). Instead of changing the Arctic sea-ice extent the Antarctic sea-ice cover is modified.

Storms were tracked using TRACK, the algorithm developed by Hodges (1995, 1996, 1999). The ECHAM5 climatology of Southern Hemisphere storm tracks using TRACK can be found in Bengtsson et al. (2006). Bengtsson et al. (2006) find that the AGCM ECHAM5, forced by observed boundary conditions, produces results that agree well with analyses from the 40-year ECMWF Re-Analysis (ERA-40). The tracking variable used in this study is 6-hourly $850 \mathrm{hPa}$ relative vorticity. This field is chosen because it is less influenced by the background flow. It also focuses on the smaller-spatial-scale end of the synoptic range so that many more systems are generally identified, as compared to mean sea level pressure, which focuses on the large-scale end (Hoskins and Hodges 2002). Relative vorticity is also related to wind speed because it is the vertical component of the curl of the relative velocity. Once cyclones are identified as local maxima in the relative vorticity fields, the correspondence between the feature points in consecutive time steps is determined by the minimization of a cost function (see Hodges (1995) for more details). The resultant storm data was filtered to retain only those systems that last longer than 2 days and travel further than $1,000 \mathrm{~km}$. Two tracking output variables were retained for analysis: (a) track density—number of storm 
Fig. 1 a The projected reduction (\%) in July to September sea-ice concentration between ECHAM5/MPI-OM IPCC SRESA1B scenario for 2081-2099 and present-day climatology (1981-1999). b Same as a but for the sensible plus latent heat-flux. Positive values indicate a heat flux from the ocean into the atmosphere. Only upward fluxes (ocean to atmosphere) are shown. c The difference in sensible plus latent heat input to the atmosphere from the ocean between the two experiments. The heat forcing is area-weighted and averaged over all sea-ice and water grid points poleward of $55^{\circ} \mathrm{S}$. Units are in $\mathrm{Wm}^{-2}$

(a) sea ice concentration anomaly JAS [in \%]

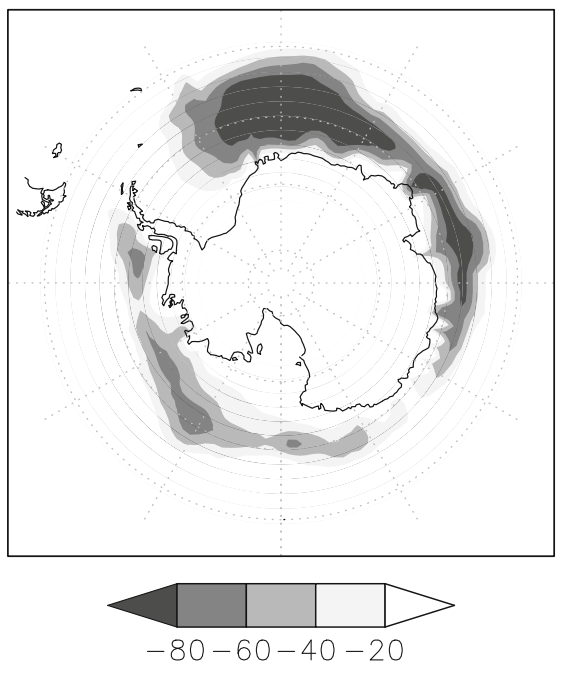

(b) heat-flux anomaly JAS $\left[\mathrm{W} / \mathrm{m}^{2}\right]$

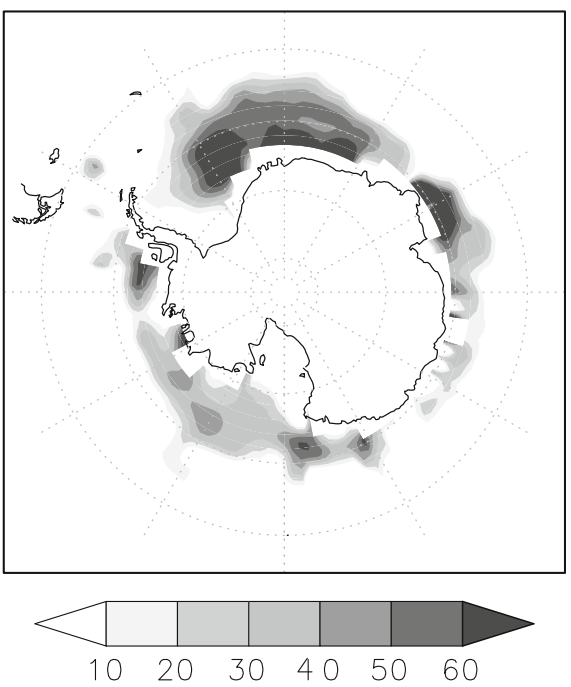

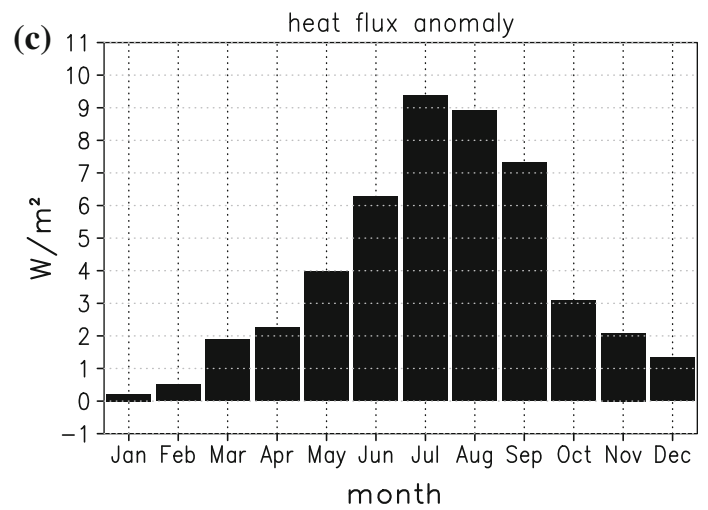

tracks through a region per month, and (b) mean intensity-mean strength of the vortices. The $5 \%$ significance level for the difference plots are computed using a permutation Monte Carlo approach (for details see Bengtsson et al. 2006; Mesquita et al. 2010).

\section{Results}

The winter (JAS) $500 \mathrm{hPa}$ geopotential height (GPH) field response to the reduced Antarctic sea-ice concentrations is summarised in Fig. 2a. The $500 \mathrm{hPa}$ GPH response has a characteristic annular structure with positive values over the central Antarctic surrounded by negative values equator-ward of $\approx 60^{\circ} \mathrm{S}$. Similar patterns in other height levels indicate an equivalent barotropic structure of the mean response (see Fig. 11; a detailed discussion of the figure follows later). A closer inspection of the vertical structure of the temperature response shows a strong and shallow heating over latitudes where sea ice has been reduced and a significant cooling response in the mid-troposphere at mid- latitudes (see Fig. 3). Figure 2a shows that the winter spatial $500 \mathrm{hPa}$ GPH response projects substantially onto the SAM-indicated by the contours. The SAM has been defined as the leading EOF of the $500 \mathrm{hPa}$ GPH in the present-day integration. The EOF has been computed over the area from $20^{\circ} \mathrm{S}$ poleward. To quantify how much of the GPH response projects onto the SAM we have spatially regressed the smoothed (for details see caption Fig. 2b) daily GPH response onto the leading $500 \mathrm{hPa}$ GPH EOF in winter (JAS). Figure 2b shows the daily regression coefficients. At the beginning of September a substantial part of the $500 \mathrm{hPa} \mathrm{GPH}$ response projects onto the leading mode (SAM). The dipole-like structure in the GPH response is associated with changes in the mid-latitude storm track. Figure $4 \mathrm{a}$ shows the spatial $850 \mathrm{hPa}$ track-density change in September and Fig. 5a represents the zonal mean September response in the track density. The vertical dashed line in Fig. 5a indicates the latitude of the maximum zonal mean storm track density in the present-day integration. Figures $4 \mathrm{a}$ and $5 \mathrm{a}$ show an equatorward shift of the storm track in the simulation with the reduced projected sea-ice 


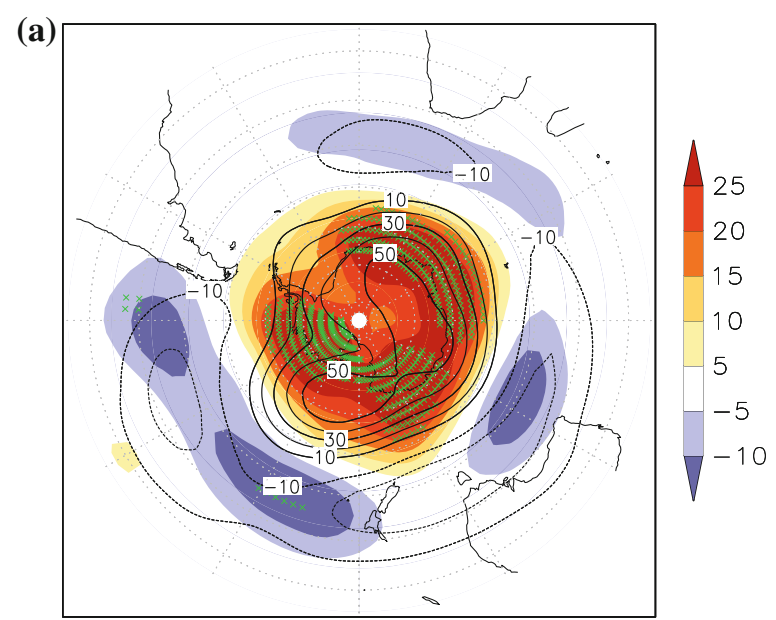

(b)

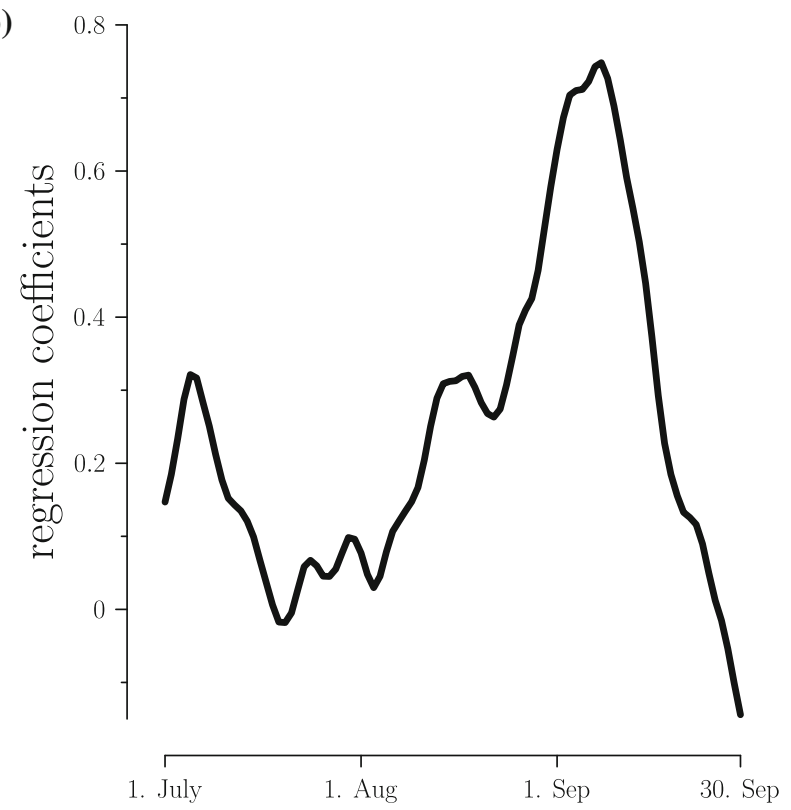

Fig. 2 a Color The winter mean (JAS) response in $500 \mathrm{hPa}$ geopotential height in [gpm]. Areas statistically significant at the $95 \%$ confidence level are marked by green crosses. The superimposed contour lines show the negative phase of the SAM-first EOF of winter (JAS) $500 \mathrm{hPa}$ geopotential height anomalies poleward of $20^{\circ} \mathrm{S}$ in the present-day integration. Solid lines are positive anomalies and dashed are negative in [gpm]. b Daily regression coefficients obtained by regressing 30-year averaged smoothed daily mean values of the $\mathrm{GPH}_{500}$ response onto the leading winter (JAS) $\mathrm{GPH}_{500}$ EOF in the present-day integration. A 10-day filter was applied on the $Z_{500}$ response data prior to the regression

cover. The storm track is enhanced approximately north of $50^{\circ} \mathrm{S}$ and reduced south of it (Fig. 5a). Figures $4 \mathrm{~b}$ and $5 \mathrm{~b}$ are the corresponding for the September precipitation response. The precipitation response also indicates an equatorward shift when the Antarctic sea ice is reduced. In addition, it shows a substantial increase of precipitation where the sea ice has been removed approximately around $65^{\circ} \mathrm{N}$. In the mid-latitudes the zonal mean distribution of the precipitation response follows that of the storm track changes (see Fig. 5a, b). The zonal-mean wind response to the reduced Antarctic sea-ice cover shows an equatorward shift of the mid-latitude SH tropospheric jet. The shading in Fig. 6 shows the response in the zonal-mean zonal wind and the crosses mark significant changes according to a two-tailed $t$ test assuming 30 independent samples in each experiment (equivalent to $58^{\circ}$ of freedom). The contour lines show the zonal-mean wind in the present-day integration. All winter months show a dipole-like wind anomaly pattern with increasing amplitudes from July until September (note that also in July a dipole-like anomaly pattern is simulated but is not visible in Fig. 6, because of the chosen common contour levels). In September the zonal-mean wind response shows a significant dipole structure reminiscent of wind anomalies associated with the SAM (see e. g. Limpasuvan and Hartmann 2000). The seasonal mean (July to September) again shows a robust dipole-like structure. The equivalent barotropic structure of the wind change suggests that this shift is caused by changes in the eddy momentum fluxes (Limpasuvan and Hartmann 2000). To further investigate the role of the eddies we use the quasi-geostrophic conventional Eulerian mean framework of zonal-mean momentum balance (see chapter 10 in Holton (2004)):

$\frac{\partial[u]}{\partial t}-f[v]-R=-\left(r_{0} \cos ^{2} \phi\right)^{-1} \frac{\partial \cos ^{2} \phi\left[u^{\prime} v^{\prime}\right]}{\partial \phi}$

where brackets denote zonal mean values, primes the eddies, $u$ the zonal wind component, $v$ the meridional wind component and $R$ the drag. The eddies are divided into transient and stationary waves. The transient eddies are defined as the temporal deviations from the monthly means and the stationary eddies are the zonal anomalies from the monthly means. The total eddy forcing includes both stationary wave and transient wave contributions. The meridional cross sections of the anomalous transient eddy momentum forcing (Fig. 7) resembles a dipole-like pattern consistent with the zonal-mean zonal wind change. The mid-latitude dipole of the transient zonal mean eddymomentum convergence response is located near $250 \mathrm{hPa}$ with enhanced convergence north of approximately $48^{\circ} \mathrm{S}$ and reduced south of it indicative for a reduced poleward eddy momentum flux across this latitude. The centers of the anomalous transient eddy momentum forcing dipole nearly coincide with the latitude of the zonal wind anomalies shown in Fig. 6. The pattern of the anomalous transient eddy momentum forcing shows, especially on the poleward side, agreement with that associated with a negative SAM which is shown by the contour lines in Fig. 7-the difference in transient eddy momentum forcing between the composite of negative winter SAM months (below -1 standard deviation) and climatology in the present-day simulation. The forcing due to the eddy 
Fig. 3 Zonally averaged vertical cross section of the temperature response in

$[\mathrm{K}]$ (projected minus presentday). Crosses indicate statistically significant changes at the $95 \%$ confidence level according to a two-tailed $t$ test. a response for July, $\mathbf{b}$ response for August, c response for September, d July to September seasonal mean response


momentum fluxes appears to maintain the wind anomalies in the upper troposphere and balance the Coriolis torques associated with the anomalous mean meridional circulation (see Eq. (1)). The properties of the barotropic eddy forcing can be summarized by vertically averaging the forcing between 700 and $100 \mathrm{hPa}$. Decomposing the anomalous barotropic eddy forcing profile into its stationary and transient components reveals that the transient as well as the stationary component have a dipole-like structure, and that the anomalous transient eddy momentum forcing is larger than the stationary wave contribution on the poleward flank (see Fig. 8a). The relative strong contribution of the stationary eddies is in contrast to e. g. the findings of Limpasuvan and Hartmann (2000). The equatorward shift of the mid-latitude circulation is also visible in the mean meridional circulation (Ferrel cell). Figure $8 \mathrm{~b}$ shows the mass streamfunction of the present-day integration as contour lines and the response in the mass streamfunction in colours. A dipole-like structure is recognisable in the mid-latitudes indicative of an equatorward shift of the Ferrel cell.

Mid-latitude weather systems are believed to have their origin in processes encapsulated in the theory of baroclinic instability. A widely used measure of the baroclinicity is provided by the Eady growth rate (Hoskins and Valdes 1990):

$\sigma=0.31 f\left|\frac{\partial \mathbf{v}}{\partial z}\right| N^{-1}$

where $\mathbf{v}$ is the horizontal wind vector, $z$ the height, $f$ the Coriolis parameter and $N$ the Brunt-Väisälä frequency. The projected Eady growth rate at $850 \mathrm{hPa}$ in winter (JAS) is reduced in the southerly mid-latitudes especially between approximately $30^{\circ} \mathrm{W}$ and $90^{\circ} \mathrm{E}$ (Fig. 9a). The reduction of the projected winter Eady growth rate in the mid-latitudes is mainly related to the poleward shift of the sea-ice edge (defined where the SIC is $15 \%$ ) and the associated reduction of the $850 \mathrm{hPa}$ meridional temperature gradient which is shown in Fig. 9b (also compare Fig. 3). The Eady growth rate (Fig. 9a) is especially reduced in the zonal band between approximately $60-50^{\circ} \mathrm{S}$ due to the poleward retreat of the ice edge. This is the latitudinal band where the strongest reduction in the eddy momentum divergence is simulated in the upper troposphere (Fig. 7). A closer look reveals that the projected change of the $850 \mathrm{hPa}$ Eady growth rate in the $\mathrm{SH}$ mid-latitudes during the winter (JAS) is always negative but not uniform in time. The largest reduction in the Eady growth rate occurs approximately in the first 2 weeks of September agreeing well with the fact that the largest projection of the GPH response onto the SAM is seen in the first half of September (Fig. 2b). This is highlighted in Fig. 10a which shows the $850 \mathrm{hPa}$ daily zonal mean Eady growth rate change averaged from 60 to $50^{\circ} \mathrm{S}$ from first of July until the end of September.

What is the cause of the change in the Eady growth rate? Fig. 10b shows the $850 \mathrm{hPa}$ Eady growth rate change due to the vertical change of the zonal wind only (black curve). The $850 \mathrm{hPa}$ Eady growth rate change (black curve) follows the meridional $850 \mathrm{hPa}$ temperature gradient change (red curve) quite closely. The blue curve shows the corresponding change of the surface meridional temperature gradient. It is evident that throughout the whole winter season the surface meridional temperature gradient in this area is reduced, leading to a generally decreased $850 \mathrm{hPa}$ Eady growth rate (Fig. 10b). Despite the fact that the reduction of the surface meridional temperature gradient is weaker in September than in August, there is a particular strong reduction of the $850 \mathrm{hPa}$ Eady growth rate at the beginning of September. This shows that the $850 \mathrm{hPa}$ Eady 
(a)
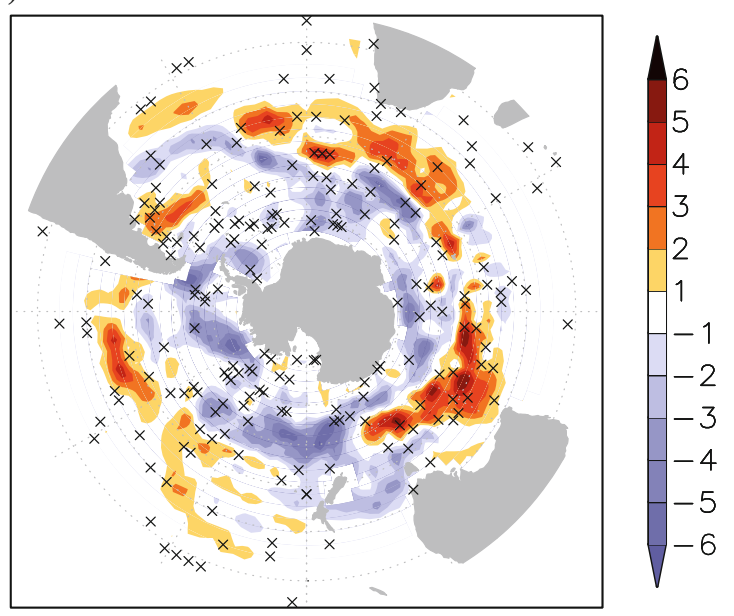

(b)
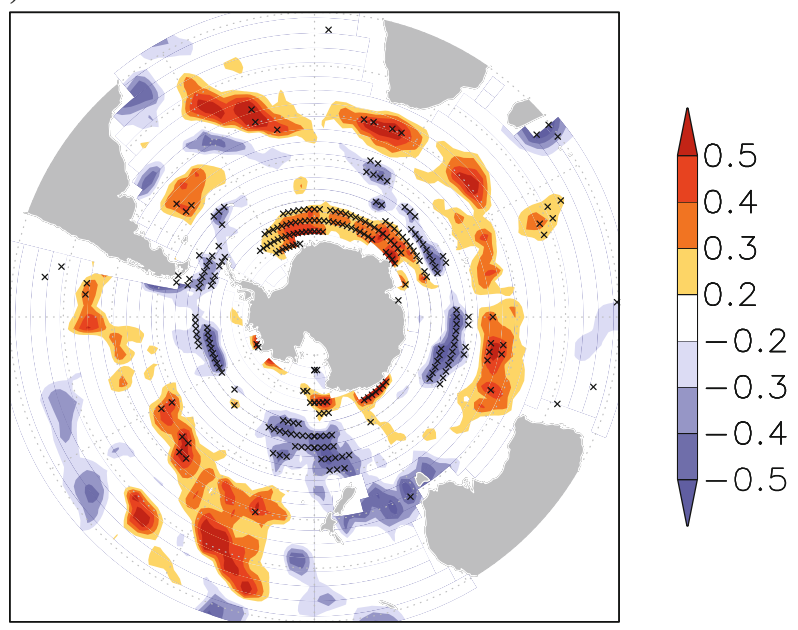

Fig. 4 a $850 \mathrm{hPa}$ track-density response in September. Densities are number density per month per unit area, where the unit area is equivalent to a $5^{\circ}$ spherical cap $\left(\approx 1 \times 10^{-6} \mathrm{~km}^{-2}\right)$. The black crosses indicate regions where the $p$ values are less than $5 \%$ (see text for details). b September precipitation response in $\mathrm{mm} /$ day. Areas statistically significant at the $95 \%$ confidence level according to a two-tailed $t$ test level are marked by black crosses

growth rate does not instantaneously follow the change in the surface boundary conditions. The anomalous meridional surface temperature gradient reduction weakens less with height in the lower troposphere in September than in the other winter months.

\subsection{Direct linear response}

The previous section showed that the sea-ice anomalies substantially impact the genesis of baroclinic eddies and that the mean response is therefore characterised by a barotropic structure. In this sub-section the focus is on the "direct" thermodynamic effect of the sea-ice anomalies on the atmosphere. Especially locally-where the strongest (a)
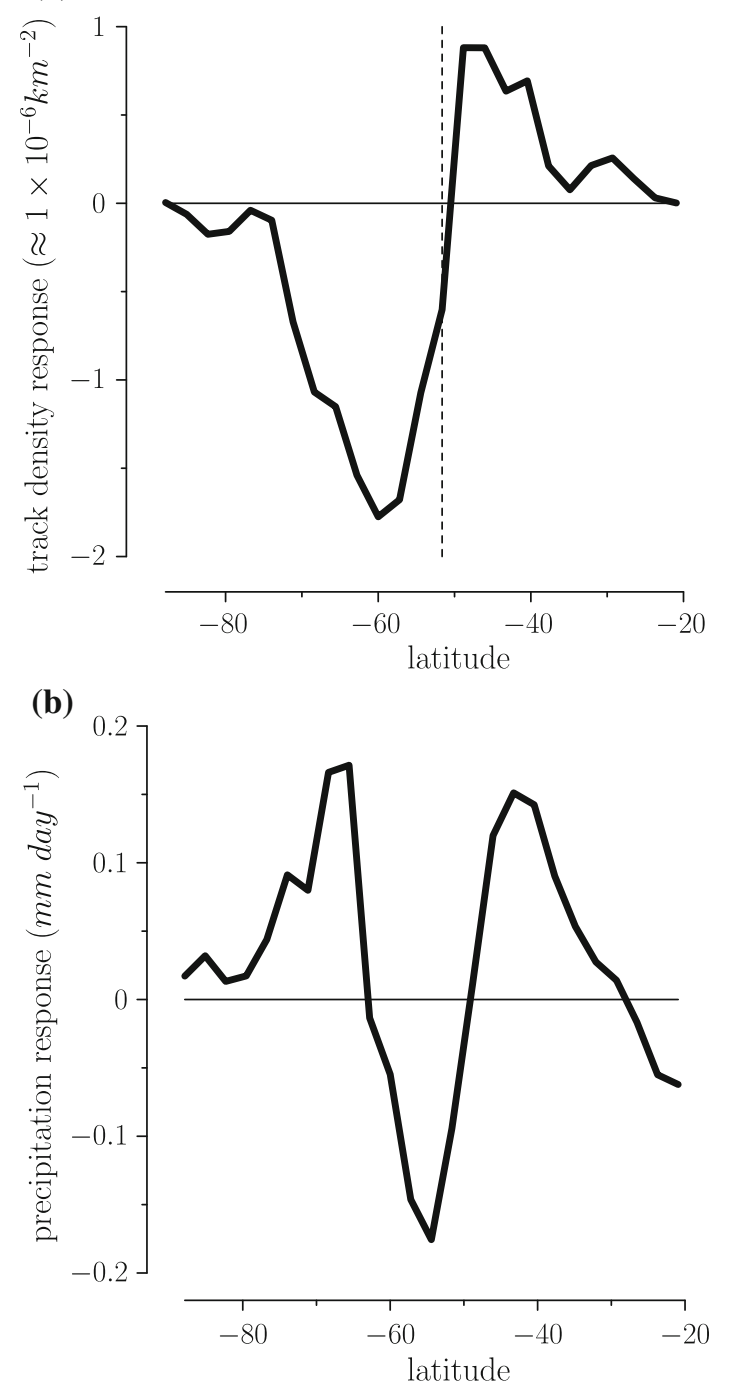

Fig. 5 a The thick black curve shows the zonal mean of the $850 \mathrm{hPa}$ track-density response in September. The dashed line indicates the latitude of the maximum zonal mean track density in the present-day simulation in September $\left(\approx 1 \times 10^{-6} \mathrm{~km}^{-2}\right)$. b September zonal mean precipitation response in $\mathrm{mm}$ /day

reduction in the heat flux occurs (see Fig. 1b)—a stronger "direct" imprint of the sea-ice anomalies is expected compared to the more remote mid-latitudes where the baroclinicity reduction dominates. To further analyse the September response, a framework similar to that introduced by Deser et al. (2004) is applied. The September response is separated into the direct linear response and the indirect response. The indirect response is the projection of the total response onto the leading EOF (SAM) in the present-day integration using spatial regression. The EOF is scaled by the spatial regression coefficient between the SAM and the total response to obtain the indirect response. The direct response is the residual: subtraction of the scaled EOF pattern from the total response field. The leading EOF has been computed 
Fig. 6 Zonally averaged vertical cross section of the zonal wind response in $[\mathrm{m} / \mathrm{s}]$ (projected minus present-day). Crosses indicate statistically significant changes at the $95 \%$ confidence level according to a two-tailed $t$ test. The contour lines show the zonally averaged zonal mean wind in the presentday integration. a response for July, b response for August, c response for September, d July to September seasonal mean response
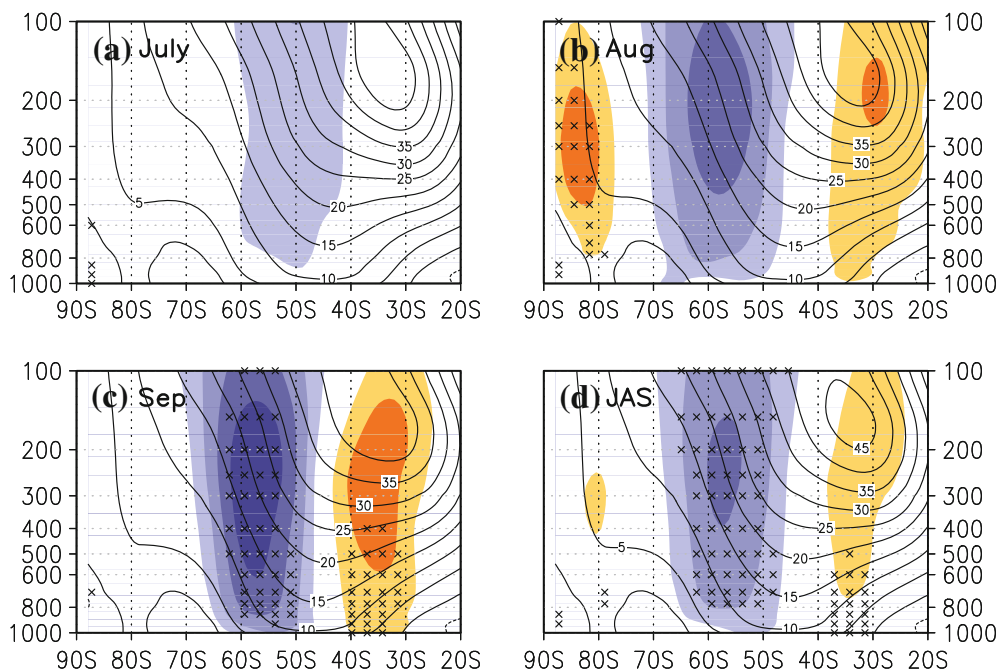

gOS 8OS TOS 6OS 5OS 4OS 30S $20 \mathrm{~S}$

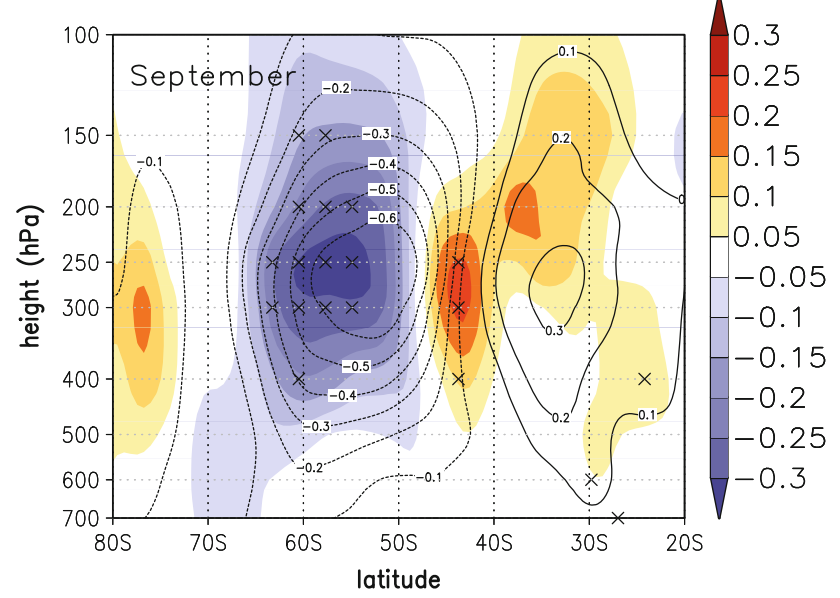

Fig. 7 September difference of the zonal mean wind forcing due to changes in the transient eddy momentum flux divergence in units of $\mathrm{ms}^{-1}$ day $^{-1}$. Statistically significant changes at the $95 \%$ confidence level according to a two-tailed $t$ test are marked by black crosses. The contour lines show the transient eddy momentum flux divergence for a negative SAM composite (see text for details)

individually for the different height levels. The results do not change when the forcing region is excluded from the spatial regression computation (not shown). Neither residual pattern resembles any of the higher-order EOFs in the present-day run, suggesting that the residual is indeed a direct, forced response and not an internal mode.

The direct linear surface GPH response (Fig. 11e) is dominated by a low (indicated by the green L) downstream of the major warming. The low transports cold Antarctic air to the major heating region and helps to cool the warming induced by the removal of the sea-ice. The upper tropospheric direct linear response shows a weak ridge above the major heating anomaly (Fig. 11f). Hence, the direct response shows a weak baroclinic structure.
We show that the direct response is consistent with linear quasi-geostrophic theory in the sense that the surface response is situated downstream of the imposed heating anomaly. The basis for our discussion of the direct linear response to thermal forcing is the linearised-about the zonal-mean-thermodynamic energy equation assuming steady state (see Hoskins and Karoly 1981):

$\overbrace{\underbrace{\bar{u} \frac{\partial \theta^{\prime}}{\partial x}}_{\mathrm{A} 2}+\underbrace{v^{\prime} \frac{\partial \bar{\theta}}{\partial y}}_{\mathrm{B} 2}+\underbrace{\omega^{\prime} \frac{\partial \bar{\theta}}{\partial p}}_{\mathrm{C} 2}=\underbrace{\frac{Q}{c_{p}} \frac{\theta}{T}}_{\mathrm{D} 2}}^{\text {thermodynamic energy equation }}$

$A 2=$ zonal temperature advection

$B 2=$ meridional temperature advection

$C 2=$ vertical temperature advection

$D 2$ = diabatic term

The steady-state linearised quasi-geostrophic thermodynamic energy equation (Eq. (3)) requires that the heating must be offset by horizontal $\left(\bar{u} \frac{\partial \theta^{\prime}}{\partial x}\right.$ and $\left.v^{\prime} \frac{\partial \bar{\theta}}{\partial y}\right)$ and/or vertical $\left(\omega^{\prime} \frac{\partial \bar{\theta}}{\partial p}\right)$ temperature advection. In mid-latitudes, horizontal temperature advection is the dominant term, because of relative large horizontal temperature gradients and convection not being as deep as in the tropics (Holton 2004). In our case, the heating is largely balanced by cold air advection from Antarctica. One way to advect cold polar air is that a low is positioned east of the heating anomaly. This can be seen by looking at the steady-state linearised quasi-geostrophic thermodynamic energy equation (Eq. (3)): the heating $\left(\frac{Q}{c_{p}} \frac{\theta}{T}>0\right)$ can be balanced by $v^{\prime} \frac{\partial \bar{\theta}}{\partial y}>0$. Since the meridional temperature gradient is positive $\left(\frac{\partial \bar{\theta}}{\partial y}>0\right)$ on the Southern Hemisphere, the eddy meridional 

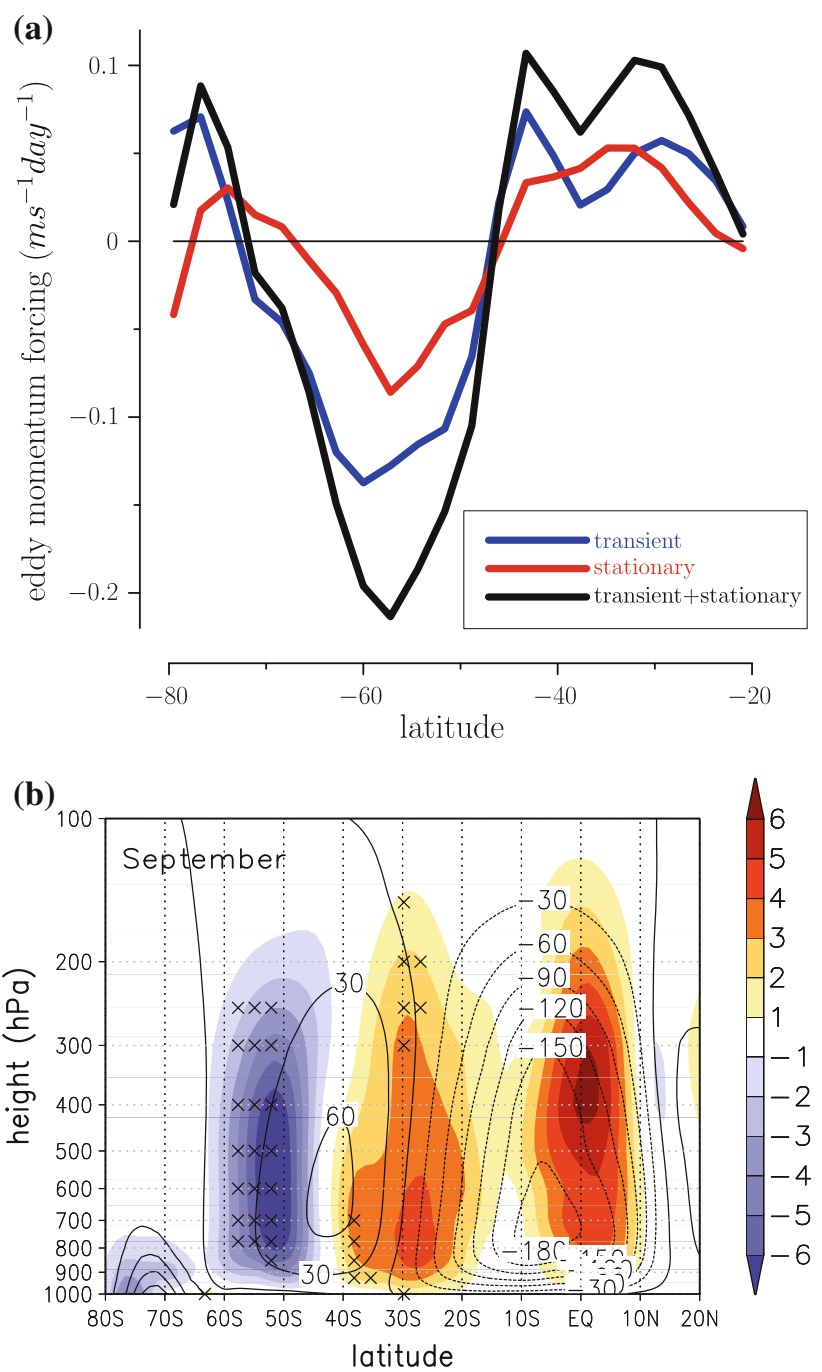

Fig. 8 a Vertically averaged (700-100 hPa) September difference of the mean zonal wind forcing due to changes in the transient (blue), stationary (red) and transient plus stationary (black) eddy momentum flux divergence in units of $\mathrm{ms}^{-1} \mathrm{day}^{-1}$. b The colouring shows the September difference in the mass streamfunction-northward mass flux response in units of $10^{9} \times \mathrm{kgs}^{-1}$. Statistically significant changes at the $95 \%$ confidence level according to a two-tailed $t$-test are marked by black crosses. The contours present the September mass streamfunction in the present-day integration in units of $10^{9} \times \mathrm{kgs}^{-1}$

motion $\left(v^{\prime}\right)$ has to be positive over the heating anomaly. This can be achieved by a surface low to the east of the heat source. The steady-state linearised quasi-geostrophic thermodynamic energy equation explains the low (green L) east of the major heating in our direct response shown in Fig. 11e. In addition, the heating can be balanced by advection of anomalous cold air into the heating area by the zonal mean circulation and by downstream advection of anomalous warm air by the zonal mean circulation $\left(\bar{u} \frac{\partial \theta^{\prime}}{\partial x}\right)$. For this mechanism to work, it will require anomalous cooler low level air upstream of the heating anomaly. Figure 12 shows the eddy-zonal mean subtracted- (a)

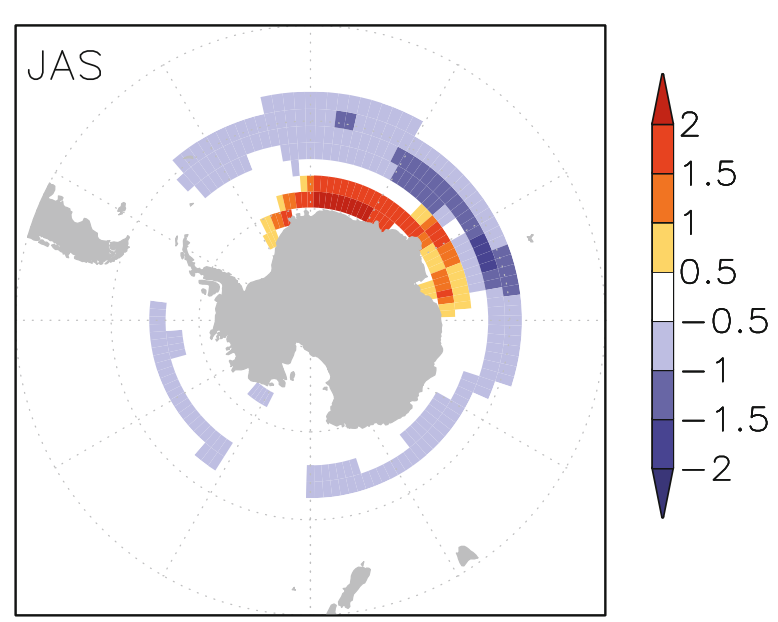

(b)

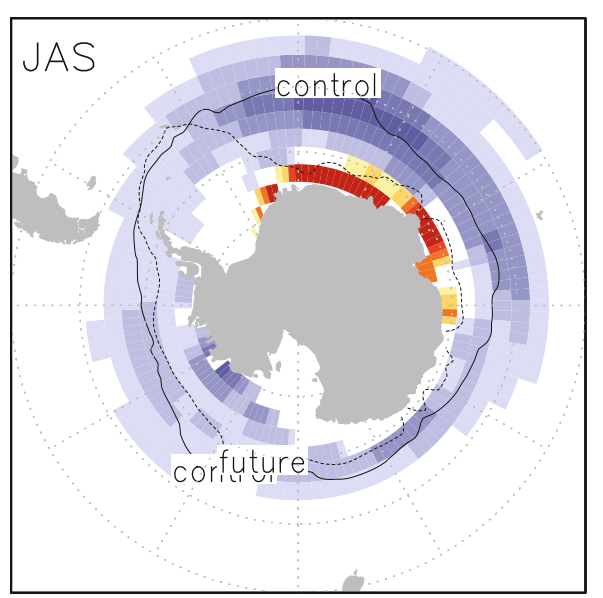

1.25

0.75

$-0.5$

$-0.25$

$-0.25$

$-0.5$

$-0.75$

$-1$

$-1.25$

Fig. 9 a Winter (JAS) spatial change of the Eady growth rate at 850 $\mathrm{hPa}$ in units of $1 \times 10^{-6} \mathrm{~s}^{-1}$. b Change of the winter (JAS) $850 \mathrm{hPa}$ meridional temperature gradient in units of $1 \times 10^{-6} \mathrm{~K} / \mathrm{m}$. The two lines show the sea-ice edge for the present-day (solid line) and the future experiment (dashed line)-for more details see text. Only significant changes of the Eady growth rate and the meridional temperature gradient at the $95 \%$ confidence level according to a twotailed $t$ test are shaded

temperature response. There is anomalous cool air west of the major heating region. This leads to cold air advection by the zonal wind into the major warming area. In addition, the figure makes it clear that warm air is transported away/ downstream from the major heating region by the zonal wind.

The direct GPH response shows a weak baroclinic structure with the upper tropospheric ridge located over the major heating region (see Fig. 11e, f). In contrast, the quasi-geostrophic model/theory shows the mid-to-upper tropospheric anticyclone located downstream of the heating (see e. g. Hoskins and Karoly 1981). The mid-to-upper level high might be explained with the hypsometric equation, 
(a)

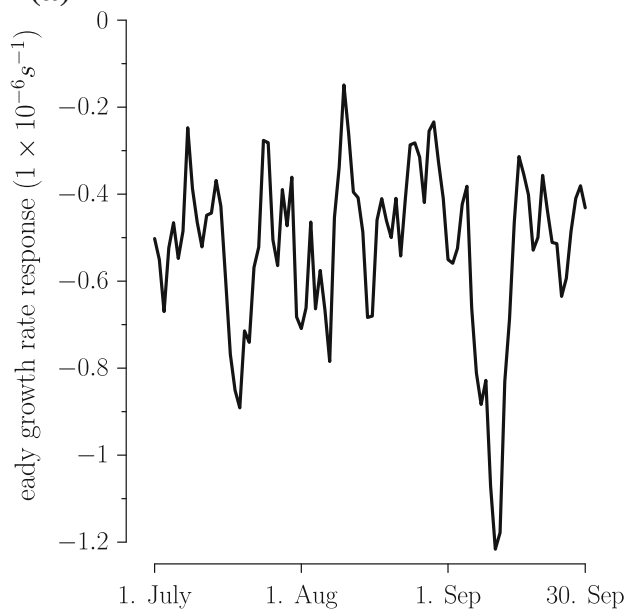

Fig. 10 a Area-averaged $\left(0^{\circ} \mathrm{E}-360^{\circ} \mathrm{W}\right.$ and $\left.60-50^{\circ} \mathrm{S}\right)$ change in the Eady growth rate from 1st of July to 30th of September at $850 \mathrm{hPa}$ in units of $1 \times 10^{-6} \mathrm{~s}^{-1}$. b Black curve: area-averaged $\left(0^{\circ} \mathrm{E}-360^{\circ} \mathrm{W}\right.$ and $60-50^{\circ} \mathrm{S}$ ) change in the Eady growth rate due to the vertical change

$\Delta z=\frac{R\langle T\rangle}{g} \ln \left(\frac{p_{1}}{p_{2}}\right)$.

An increase in the mean temperature $\langle T\rangle$ between the pressure levels $p_{1}$ and $p_{2}$ will increase the layer thickness $z$. In our simulation, the warmest anomalous air above the surface (not shown) is located downstream of the major heating region (see contour line in Fig. 11e) in agreement to the quasi-geostrophic model. Nevertheless, the strongest positive GPH anomalies are above the major heating region (see Fig. 11e, f).

\section{Conclusions}

The impact of a reduced Antarctic sea-ice cover on the $\mathrm{SH}$ wintertime atmospheric circulation has been investigated by forcing the AGCM ECHAM5 with a present-day and a projected future seasonal cycle of Antarctic sea ice. In this study, we have considered the following scientific questions, as outlined in the introduction:

1. Does a reduction in Antarctic sea-ice cover have a substantial impact on the mid-latitude $\mathrm{SH}$ atmospheric circulation?

2. Are these changes in the mid-latitude $\mathrm{SH}$ atmospheric circulation in "analogy" to previous experiments with reduced Arctic sea-ice?

The results of this study show that a projected Southern Hemispheric sea-ice reduction has a substantial impact on the mid-latitude jet, the storm track and the SAM in the SH winter season. Through changes in the near-surface baroclinicity and therefore the genesis of mid-latitude eddies, a (b)

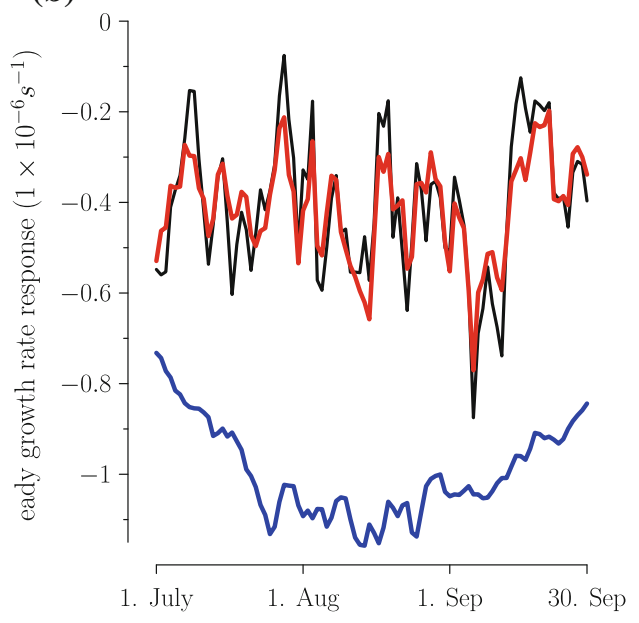

of the zonal wind only $(\partial u / \partial z)$ from 1st of July to 30th of September at $850 \mathrm{hPa}$ in units of $1 \times 10^{-6} \mathrm{~s}^{-1}$. Red/blue curve: area-averaged $\left(0^{\circ} \mathrm{E}-360^{\circ} \mathrm{W}\right.$ and $\left.60-50^{\circ} \mathrm{S}\right)$ meridional temperature gradient change at $850 \mathrm{hPa} /$ surface over the same period in units of $1 \times 10^{-6} \mathrm{~K} / \mathrm{m}$

reduction of SH sea ice leads to an equatorward shift of the mid-latitude jet and the storm track. The weakening of the SAM, the equatorward shift of the jet and the storm track shows remarkable "analogy" to the Arctic sea-ice experiments by Seierstad and Bader (2009). Both studies suggest that a reduction in hemispheric sea-ice causes a late winter weakening of the dominant atmospheric large-scale circulation pattern in the hemisphere where the sea-ice is reduced. The response during the winter season is largest in the first 2 weeks of September, in line with the fact that the strongest reduction in the $850 \mathrm{hPa}$ Eady growth rate occurs at the beginning of September. Importantly, this September peak cannot be explained by the instantaneous change in the boundary surface conditions. We speculate that this behavior could be caused by the fact that the response lags the forcing (see also Deser et al. 2010) or the modified background state at the beginning of September compared to the present-day simulation. This issue ought to be further investigated in future work.

The mean winter response to Antarctic sea-ice reductions found in this study compares well with the study by Menéndez et al. (1999) who also find an equatorward shift of the storm track and jet in the SH mid-latitudes. Both studies show that the meridional temperature gradient is weaker in the reduced sea-ice integrations. This causes a weakening of baroclinic processes, which manifest in a reduction of the Eady growth rate.

However, our findings are in contrast to the study by Kidston et al. (2011), who suggests that any future decreases in Antarctic sea ice are unlikely to have a profound effect on the Southern Hemisphere mid-latitude circulation. Kidston and Gerber (2010) show that an equatorward bias in the position of the $\mathrm{SH}$ jet in models is 
Fig. 11 Decomposition of the total September GPH responses $(1,000 \mathrm{hPa}(\mathbf{a})$ and $300 \mathrm{hPa}(\mathbf{b}))$ into a component $(1,000 \mathrm{hPa}$ (c) and $300 \mathrm{hPa}(\mathbf{d}))$ that projects onto the leading EOF (SAM) of the present-day run and the residual $(1,000 \mathrm{hPa}$ (e) and $300 \mathrm{hPa}(\mathbf{f})$ ) from that projection (direct response). The units are in [gpm]. In figure (e) the contour line shows the area where the surface heatflux anomaly exceeds $40 \mathrm{Wm}^{-2}$ (a) Total response $(1000 \mathrm{hPa})$

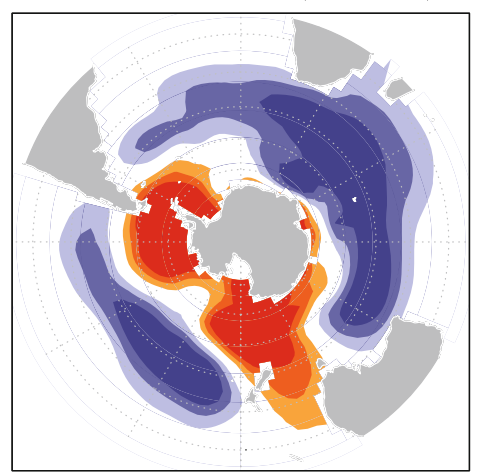

(c) Internal Mode Projection (1000hPa)

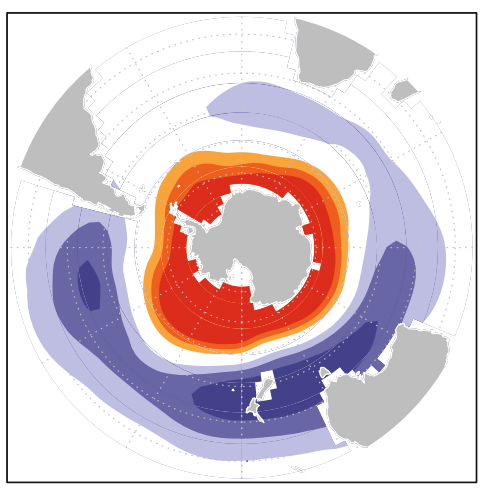

(e) Residual (1000hPa)



(b) Total response $(300 \mathrm{hPa})$

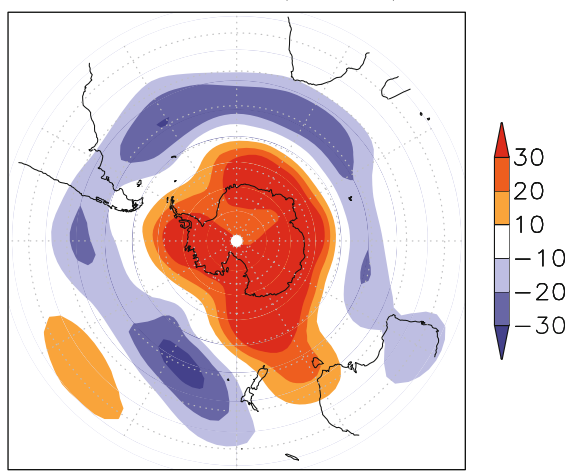

(d) Internal Mode Projection $(300 \mathrm{hPa})$

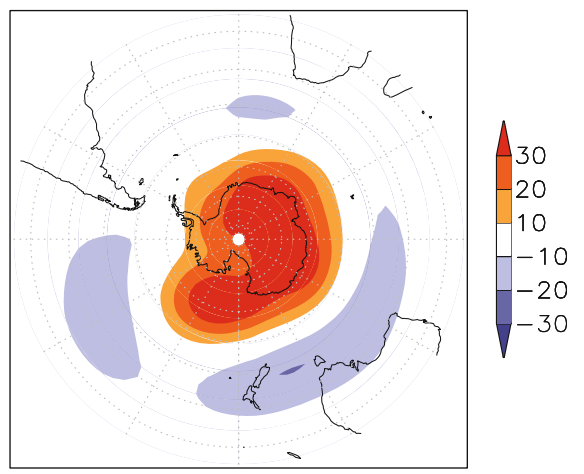

(f) Residual $(300 \mathrm{hPa})$

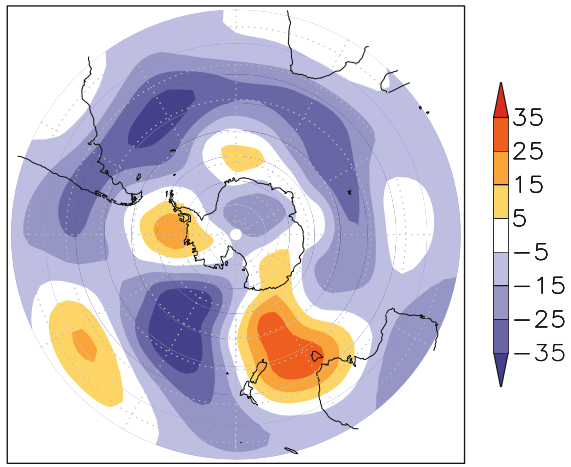

associated with both enhanced persistence of the annular mode, and an increased poleward shift of the jet under global warming conditions. A larger equatorward bias in the position of the $\mathrm{SH}$ eddy-driven jet in a model might make it less sensitive to sea-ice reductions, because it is further away from the location where the baroclinicity (sea ice) is changed. Further analysis is needed concerning the seasonality of the response and to what extent these differences are due to the different models used in the studies and/or if the actual sea-ice anomaly pattern matters for the response.
Our study suggests that if there is an imprint of the forcing from sea-ice anomalies it is likely to be found in late winter. Using the coupled version of the model used here, the ECHAM5/MPI-OM, Bengtsson et al. (2006) reported a clear poleward shift of the SH storm tracks in JJA in the SRES A1B future scenario. Since we found an equatorward shift of the storm track, there is little to suggest that these storm track responses are dominated by seaice anomalies. This is not surprising as we find only a moderate change in the mean winter storm track response. However, the study by Bengtsson et al. (2006) does not 




Fig. 12 September 1,000 hPa eddy-zonal mean subtracted-temperature response over the ocean in Kelvin

include the September in their winter response or even show the response in late winter alone when we get the most substantial response.

Acknowledgments We are grateful to two anonymous reviewers and Davide Zanchettin who has done the internal review at MPI-M. The UK Meteorological Office and Hadley Centre is acknowledged for providing the HadISST $1.1-$ global SST — data-set. We also thank Dr. Kevin Hodges (University of Reading, UK) for providing the storm tracking algorithm TRACK. This work was supported by the Max Planck Society, the Federal Ministry of Education and Research in Germany (BMBF) through the research programme "MiKlip" (FKZ: 01LP1158A) and by the DecCen project funded by the research council of Norway.

\section{References}

Alexander MA, Bhatt US, Walsh JE, Timlin MS, Miller JS, Scott JD (2004) The atmospheric response to realistic Arctic sea ice anomalies in an AGCM during winter. J Clim 17(5):890-905

Bader J, Mesquita MDS, Hodges KI, Keenlyside N, Østerhus S, Miles M (2011) A review on Northern Hemisphere sea-ice, storminess and the North Atlantic Oscillation: observations and projected changes. Atmos Res 101:809-834. doi:10.1016/j.atmosres.2011. 04.007

Bengtsson L, Hodges KI, Roeckner E (2006) Storm tracks and climate change. J Clim 19:3518-3543. doi:10.1175/JCLI3815.1

Brayshaw DJ, Hoskins B, Blackburn M (2008) The storm-track response to idealized SST perturbations in an aquaplanet GCM. J Atmos Sci 65(9):2842-2860. doi:10.1175/2008JAS2657.1

Deser C, Magnusdottir G, Saravanan R, Phillips A (2004) The effects of North Atlantic SST and Sea Ice Anomalies on the winter circulation in CCM3. Part II: direct and indirect components of the response. J Clim 17(5):877-889

Deser C, Tomas R, Alexander M, Lawrence D (2010) The seasonal atmospheric response to projected Arctic sea ice loss in the late twenty-first century. J Clim 23(2):333-351
Hodges KI (1995) Feature tracking on the unit sphere. Mon Weather Rev 123:3458-3465. doi:10.1175/1520-0493(1995)123<3458: FTOTUS $>2.0 . \mathrm{CO} ; 2$

Hodges KI (1996) Spherical nonparametric estimators applied to the UGAMP model integration for AMIP. Mon Weather Rev 124: 2914-2932. doi:10.1175/1520-0493(1996)124<2914:SNEATT> 2.0.CO;2

Hodges KI (1999) Adaptive constraints for feature tracking. Mon Weather Rev 127:1362-1373. doi:10.1175/1520-0493(1999)127 $<1362$ :ACFFT $>2.0 . \mathrm{CO} ; 2$

Holton J (2004) An introduction to dynamic meteorology. 4th edn. International Geophysics Series. Elsevier, Amsterdam

Hoskins BJ, Hodges KI (2002) New perspectives on the Northern Hemisphere winter storm tracks. J Atmos Sci 59:1041-1061. doi:10.1175/1520-0469(2002)059<1041:NPOTNH >2.0.CO;2

Hoskins BJ, Karoly DJ (1981) The steady linear response of a spherical atmosphere to thermal and orographic forcing. J Atmos Sci 38:1179-1196. doi:10.1175/1520-0469(1981)038<1179: TSLROA $>2.0 . C O ; 2$

Hoskins BJ, Valdes PJ (1990) On the existence of storm-tracks. J Atmos Sci 47(15):1854-1864. doi:10.1175/1520-0469(1990) 047<1854:OTEOST $>2.0 . \mathrm{CO} ; 2$

IPCC (2007) Climate change 2007: The physical science basis. Contribution of working group I to the fourth assessment report of the intergovernmental panel on climate change In: Solomon S, Qin D, Manning M, Chen Z, Marquis M, Averyt KB, Tignor M, Miller HL. Cambridge University Press, Cambridge

Limpasuvan V, Hartmann DL (2000) Wave-maintained annular modes of climate variability. J Clim 13(24):4414-4429. doi: 10.1175/1520-0442(2000)013<4414:WMAMOC $>2.0 . \mathrm{CO} ; 2$

Kidston J, Gerber EP (2010) Intermodel variability of the poleward shift of the austral jet stream in the CMIP3 integrations linked to biases in 20th century climatology. Geophys Res Lett 37:L09708. doi:10.1029/2010GL042873

Kidston J, Taschetto AS, Thompson DWJ, England MH (2011) The influence of Southern Hemisphere sea-ice extent on the latitude of the mid-latitude jet stream. Geophys Res Lett 38(15). doi: 10.1029/2011GL048056

Kushnir Y, Robinson WA, Blad I, Hall NMJ, Peng S, Sutton R (2002) Atmospheric GCM response to extratropical SST anomalies: synthesis and evaluation. J Clim 15(16):2233-2256

Magnusdottir G, Deser C, Saravanan R (2004) The effects of North Atlantic SST and Sea Ice Anomalies on the winter circulation in CCM3. Part I: Main Features and Storm Track Characteristics of the response. J Clim 17(5):857-876

Menéndez CG, Serafini V, Le Treut H (1999) The effect of sea-ice on the transient atmospheric eddies of the Southern Hemisphere. Clim Dynam 15(9):659-671. doi:10.1007/s003820050308

Mesquita Michel DS, Hodges Kevin I, Atkinson David E, Bader Jürgen (2010) Sea-ice anomalies in the Sea of Okhotsk and the relationship with storm tracks in the Northern Hemisphere during winter. Tellus A (October):no-no. doi:10.1111/j.1600-0870.2010.00483.x

Rayner NA, Parker DE, Horton EB, Folland CK, Alexander LV, Rowell DP, Kent EC, Kaplan A (2003) Global analyses of sea surface temperature, sea ice, and night marine air temperature since the late nineteenth century. J Geophys Res 108(D14):4407. doi: 10.1029/2002JD002670

Roeckner E, Bäuml G, Bonaventura L, Brokopf R, Esch M, Giorgetta M, Hagemann S et al. (2003) The atmospheric general circulation model ECHAM 5. Part I. Vol. 349. MPI-Report

Seierstad Ivar A, Bader Jürgen (2009) Impact of a projected future Arctic Sea Ice reduction on extratropical storminess and the NAO. Clim Dynam 33:937-943. doi:10.1007/s00382-008-0463-x

Serreze Mark C, Holland Marika M, Stroeve Julienne (2007) Perspectives on the Arctics shrinking Sea-Ice cover. Science 315(5818):1533-1536. doi:10.1126/science.1139426 
Turner J, Overland JE, Walsh JE (2007) An Arctic and antarctic perspective on recent climate change. Int J Climatol 27(3):277293. doi:10.1002/joc. 1406
Turner J, Overland J (2009) Contrasting climate change in the two polar regions. Polar Res 28(2):146-164. doi:10.1111/j.17518369.2009.00128.x 